A. J. C. van Seters. Omgang met Zieken. Nieuwe herziene en vermeerderde uitgawe. 1950. $103 \mathrm{bl}$. Uitgewerij W. ten Have, Amsterdam. $6 / 3$ posvry.

Die titel van hierdie boek dek nie heeltemaal sy inhoud nie. Want dit is veel meer as ' $n$ handleiding vir die omgang met siekes, sy ondertitel kon gewees het: „En die omgang van die sieke met sy omgewing." Die skrywer behandel sy tema met baie kennis en toewyding. Hy skenk aandag aan die kleinste dinge en momente in die lewe van 'n lydende, wat miskien in die oë van 'n gesonde onnodig sal lyk, maar wat in die beperkte bestaan van ' $n$ fyngevoelige sieke 'n enorme betekenis kan kry. Hy aksentueer die geweldige verskil tussen die lydende en dikwels oorgevoelige sieke en die gesonde mens, wat ondanks die goeie wil nie altyd die gedagtes van 'n sieke kan volg nie. Hy gee 'n grondige bespreking van die omgang van die gesondes met 'n sieke, maar hy wys ook voortdurend op die gevaarlike toestand van 'n sieke wat maklik sy beklaenswaardige toestand kan oordryf en in sy egoisme sy familie of die verplegende personeel kan tiranniseer.

Die leser vind hier ' $n$ uitstekende handleiding vir die hoofprobleme van die siekeversorging en siekebesoek. Die skrywer gee 'n kort saamvatting van die geestesgesteldheid van die verskillende siekes. Vanaf die ligte gevalle tot die langdurige en sware siektes, gevaarlike operasies, liggaamlike gebreke ens. Sy analiese is voortrefflik en sy raad om met die afsonderlike gevalle om te gaan, verraad baie kennis, tak en liefde. Ons kry 'n afsonderlike gedeelte met tallose planne om 'n herstellende of ligte sieke besig te hou en om vir die sieke self 'n opbouende en rusgegewende besigheid te kan gee.

Die laaste twee gedeeltes van die boek handel oor die geestlike versorging van 'n sieke, met verwysing na al die moeilikhede en selfs gevare van hierdie uiters belangrike werk. Die laaste bladsydes word gewy aan die geestelike bystand van siekes vir wie geen hoop meer bestaan om gesond te word nie, dus wat voorberei moet word vir die groot afskeid. 
Die skrywer word in die hele boek gelei deur 'n diep christlike liefde єn geloof sonder dat hy die Bybel te veel siteer. Die boek adem 'n ware christlike barmhartigheid en naasteliefde.

Ons wil hierdie boekie aanbeveel vir gesondes netsoos vir siekes en in die besonder vir hulle wat die versorging van siekes tot hul lewenstaak gekies het.

Ds. Kálmán Papp.

Dr. K. H. Miskotte, De Kern van de Zaak, Toelichting bij een proeve van hernieuwd belijden (G. F. Callenbach N.V., Nijkerk 1950).

Op die voorblad van hierdie werk laat die skrywer 'n nota verskyn: „,Dit boek wil een uitleg zijn van het aan de Ned. Herv. Kerk voorgelegde geschrift ,Fundamenten en Perspectieven van belijden; een proeve van beschrijving'. Het tracht vooral op de ,religie' van het belijden te letten. Het heeft geen officieel gezag; als één der leden van de commissie van ontwerp was de schrijver meer of min ingewijd; daaraan ontleende hij de moed, een reeks artikelen te schrijven in het weekblad ,In de Waagschaal', die hier ,zeer vermeerderd' gebundeld verschijnen." - Hiermee het ons eintlik die idee van 'n merkwaardige boek oor'n nog merkwaardiger saak.

Die merkwaardige saak waaroor dit handel, is die poging om tot 'n nuwe belydenis te kom, 'n poging wat uitkristaliseer het in die bogenoemde „Fundamenten en Perspectieven". Hierdie poging het baie weerstand en kritiek uitgelok, veral in Gereformeerde kringe. En ons moet erken dat die idee van 'n nuwe belydenis by die eerste kennismaking 'n mens vreemd aandoen. Wanneer 'n mens dit egter van naderby beskou, gryp die poging jou met 'n onweerstaanbare krag aan.

Want die nuwe belydenis is nie bedoel om die "ou" belydenis, die Drie Formuliere van Enigheid, te vervang, te verdring of selfs daarmee gelykgestel te word nie. Dit doen niks af aan die handhawing van die drie belydenisgeskrifte nie. Dit is bloot die uitdrukking van 'n Kerk wat staan onder die nood van die tyd en beweeg word deur die Gees van God om meer bewus te word van sy heilige bestemming. Want die belydenis is geen akkoord van kerklike gemeenskap, geen reglement of beginselverklaring nie; maar ,,is geboren uit een geestelike beslissing, die telkens opnieuw moet worden bevestigd vanuit dezelfde geestelijke kennis, waaraan zij destijds is ontsprongen . . . Z ij is het antwoord der kerk op het Woord Gods, de dankbare erkentenis van de Waarheid, waar zij niet onder uit kan ..." (p. 8). Daarom kan die belydenis nie vir die kerk iets doods wees nie; ook nie 'n stel reëls of regulasies nie; maar die kerk moet sy belydenis lewe. As die kerk sy belydenis lewe en die belydenis is die antwoord op die Woord van God, moet die kerk steeds opnuut bely. En is dit nie per slot van rekening wat ons kerk ook maar nie doen nie? 
As 'n predikant die een of ander sekte beveg, is dit nie 'n belydenis ,,in gemeenskap met die vaders" en vanuit die Skrif nie? As ons sinode in 1945 hom teen die Kommunisme uitspreek, is dit nie ook so'n nuwe belydenis nie, hoewel negatief? Moet ons as Christene en as kerk nie gedurig opnuut bely nie? Hoewel kort kom hierdie sake tog kernagtig in die inleiding van die boek tersprake.

Wat die inhoud van die werk betref, is dit 'n uitleg van die artikels opgeneem in „Fundamenten en Perspektieven." Hierdie artikels is besonder interessant: Dit toon 'n sterk weerklank van die huidige situasie soos trouens die Drie Formuliere van Enigheid ook hulle eie tyd laat weerklink. Die artikels toon 'n sterk afkeer in alle vorme van die spekulatiewe benadering van die openbaringswaarhede en betrek hierdie waarhede geweldig sterk op die persoon self en sy lewe in gemeenskap met God (vgl. bv. art. 2 en die uitleg van die leerstuk van die beeld van God). Hierdie artikels toon ook bepaalde verskille met die Drie Formuliere, bv. die eschatologiese verwagting word sterker op die voorgrond gebring en twee hele artikels word an die plek van Israel gewy. Ook is die artikels dikwels baie meer direk op die Skrif betrokke en leef dit meer uit die Skrif uit as wat ons by die Drie Formuliere vind. Wat die styl van die formuleringe betref, is dit baie minder hoogdrawend en langademig as die Drie Formuliere - sinne wat 'n hele bladsy elk beslaan, word bv. hier nie aangetref nie.

Al hierdie dinge en die menigvuldigheid van al die ander word bekwaam en noukeurig deur Dr. Miskotte belig en uiteengeset. Die resultaat is dat 'n werk ontstaan wat vir die dogmatiek baie belangrik is. Elkeen wat 'n studie van die dogmatiek wil mak, moet van hierdie werk kennis neem. Tog is dit nie so ingewikkeld geskryw'e dat 'n normale intelligente persoon nie baie genot daaruit kan put nie. Die werk van Miskotte, wat „Fundamenten en Perspectieven” met 'n uitleg van die artikels weereens op 'n bekwame wyse aanbied, is van die grootste belang belang en behoort ' $n$ baie wye leserskring, ook in Suid-Afrika, te vind.

P. S. Dreyer.

Dr. H. J. DE Vos, Inleiding tot de Wijsbegeerte (G. F. Callenbach N.V., 1951).

Die skrywer van hierdie werk is veral bekend as godsdiens-filosoof op welke terrein hy heelwat werke gepubliseer het. In die werk waaroor ons handel, begeef hy hom nou op die gebied van die suiwere wysbegeerte. Ons kan egter deurgaans die agtergrond van die godsdiens-wysgeer merk, nie soseer in die behandelde stof of in die wyse van die behandeling daarvan nie, maar in die heenwysing na probleme van die godsdiens-wysbegeerte - 'n heenwysing wat ' $n$ mens dikwels net tussen die reëls kan lees. 
Hierdie "Inleiding tot de Wijsbegeerte" is nog een in 'n tallose ry van dergelike inleidings. Die vereiste wat ' $n$ mens aan ' $n$ inleiding tot die wysbegeerte stel, word egter in hierdie werk voldoen, en dit is meer as wat 'n mens van die meeste inleidings kan sê. Hierdie inleiding gee 'n goeie en deeglike oorsig van die terrein van die wysbegeerte: Die eerste en grootste gedeelte van die werk handel oor die wysbegeerte en sy onderdele. Hier het ons die onderafdelings: 1. Geskiedenis van van die woord en die begrip filosofie; 2. Wat wysbegeerte is; 3. Die onderdele van die wysbegeerte. Die tweede gedeelte van die werk handel in 65 bladsye oor 'n aantal verskillende wysgerige stelsels: Die materialisme, lewensfilosofie, psigies monisme, idealisme, humanisme en eksistensiefilosofie. Hierdie is maar enkele van die talle stelsels wat in die wysbegeerte bestaan, maar dit is goed dat die skrywer homself beperk het, anders sou die werk vir die doel van 'n inleiding oorlaai geword het.

Die wyse waarop die skrywer sy stof behandel, is ook bevredigend: Dit is eenvoudig, duidelik en geskrywe in 'n taal wat geen wysgerige skoling veronderstel nie. Tog bring dit die leser op 'n gemaklike en eenvoudige manier by die kern van die probleme. Wat ook belangrik is, is dat die skrywer hom nie in so'n mate deur die een of ander bepaalde standpunt laat oorheers dat sy werk daardeur uit verband geruk word nie. Hoewel 'n mens die idealisme van Hegel en ook die fenomenologie soms sien deurskemer, hou die skrywer hom aan die tradisionele benaderingswyse van probleme. Gesien van die kant van die leser wat 'n inleiding in die wysbegeerte verlang, is dit goed. Met allerlei revolusionêre beskouings en metodes behoort ' $n$ mens eers kennis te maak nadat jy die veld van die filosofie al 'n bietjie verken het. Vergeleke met die „Inleiding" van Loen wen de Vos in verstaanbaarheid en leesbaarheid en vergeleke met Jaspers se „Einführung” wen hy deur die feit dat Jaspers se werk so geheel en al in die eksistensiefilosofie staan dat die leser 'n hele wysgerige skoling nodig het om die werkie te begryp.

Een eienaardigheid van de Vos se werk moet ons hier noem: Hoewel sy behandelingswyse heeltemaal histories is, ruim hy geen plek in vir die geskiedenis van die wysbegeerte as 'n selfstandige onderdeel van die wysbegeerte nie. Elkeen van die onderdele - die woord en begrip wysbegeerte, wat wysbegeerte is, die logika, ens. - benader de Vos deur die historiese aanloop vir die gebied te gee en van daaruit tot 'n begrip te kom van waarmee hy besig is. Waarom sou hy dan die geskiedenis van die wysbegeerte uitlaat? Dit is tog ook 'n spesifieke afdeling van die wysgerige studie en het sy eie probleme waaroor 'n mens jou moet oriënteer. Ons kan hierdie boek aanbeveel vir almal wat graag met die wysbegeerte wil kennis maak en 'n begin van die studie daarvan wil maak. Veral kan ons dit aanbeveel vir studente wat met 'n eerstejaarskursus wil begin en wat georiënteer wil word op die gebied wat voorlê. Die werk is beslis die moeite werd en beter as baie van sy soort.

Dr. P. S. Dreyer. 
C. S. LewIS, Christelijke Levenshouding (Uitgeverij Ten Have N.V., Amsterdam, 1950).

C. S. Lewis is vandag een van die bekendste en knapste skrywers van Christelike kant in die Engelse wêreld. Sy roem het nie net tot die Engels-lesende publiek beperk gebly nie, maar is ook deur vertalings oor die hele wêreld versprei.

Wat besonder verfrissend van die werke van Lewis is, is dat hy ortodoks Christelik is, dat hy die gesag van die kerk en die Bybel aanvaar, hoewel hy natuurlik ook kritiek op die Kerk het. Sonder om te skroom, verkondig hy die Godheid van Christus by voorbeeld bloot op gesag van die Bybelse woord. Die drie sentrale feite vir die verspreiding van die Christelike godsdiens is vir hom die doop, geloof en die nagmaal. By iemand wat nie 'n professionele teoloog is nie, is dit 'n aangename verrassing om sulke uitsprake aan te tref. Daarom kan ons ook baie dinge waar ons teologies met Lewis verskil, verskoon.

Sy bekendste werke is "The Problem of Pain" en "The Screwtape Letters". In eg. verdedig hy die standpunt dat God die mens vry geskape het en dat die vryheid van die mens noodsaaklik op die sonde uitloop noodsaaklik omdat die mens wesenlik deur die sondeval bedorwe is. Saam met die sonde kom pyn in die wêreld en pyn is noodsaaklik om die mens die nederigheid te leer waardeur hy alleen gereed is om die verlossing van God aan te neem.

Die "Screwtape Letters" is 'n skitterende satire op die ateïste, agnostici en sg. progressiewe persone wat die Christendom as outyds beskou en liewer skeppende evolusie, kommunisme, wetenskaplike humanisme, ens. aanhang. Hy skryf hierdie satire in 'n besonder aangename en verfrissende vorm: Dit is naamlik die briewe van Uncle Screwtape, die sekretaris van die Binnelandse Departement van die Hel (of soiets), aan sy nefie, Wormwood, 'n vakleerling-duiweltjie op aarde, waarin Screwtape aan Wormwood raad gee van hoe om te werk te gaan.

Die werkie wat ons hier resenseer, is 'n vertaling van die Engelse oorspronklike „Christian Behaviour". Dit is 'n agttal radiolesings, aangevul met nog drie stukkies. Lewis se skryfstyl, geestig, gemaklik, vol verrassende uitdrukkings, hoewel soms 'n bietjie plat om by die populêre smaak aan te pas, gaan in hierdie skitterende vertaling nie verlore nie. Maar hy is hier ernstig en sy satiriese skryfwyse, wat miskien sy sterk hoedanigheid is, laat hy na. Die boekie is nie eintlik met prinsipiële sake besig nie - dit word veronderstel. So sien ons op die agtergrond van sy uiteensettings altyd die aanvaarding van die Bybel se gesag en die leerstellinge van Christus. Hy wil hier op'n heel praktiese wyse aan mense wat die Christendom eintlik nie ken nie, maar ook aan mense wat Christene is maar nog nie oor die Christelike etiek nagedink het nie, die Christelike lewenswandel uiteensit.

Hy sien as die hoofpunte van die Christelike moraal 1. die eerlike verstandhouding en harmonie tussen mens en medements; 2 die persoonlike lewenswandel van elke individu; 3 . die alomvattende doel van 
die mens as geheel: waartoe God die mens geskep het, welke koers die mense se lewe as geheel behoort in te slaan en die gehoorsaamheid aan God. Hierdie drie temas werk hy op oortuigende wyse na verskillende kante toe uit om dat te eindig met die drie laaste temas: Hoop as 'n wesenlik Christelike element en deug; geloof as die aanvaarding van outoriteit; en geloof as die persoonlike verhouding tot God waarin die mens, wat nederigheid deur pyn en mislukking van selfheiliging geleer het, in kinderlike vertroue die weg van gehoorsaamheid bewandel en sy redding in die hande van God oorlaat.

Sonder om kritiek op Lewis se beskouings te lewer, wil ons hierdie boekie anbeveel vir elkeen wat in die Christelike etiek belangstel. Die werke van Lewis kan gerus onder ons bekender word. Die werkie is mooi gebind en op pragtige paper gedruk en die vertaling is deeglik gedoen.

Dr. P. S. Dreyer.

Otro A. Dilischneider, Das Christliche Weltbild. Grundlagen und Wirklichkeit einer evangelischen Akademie (C. Bertelsmann Verlag, Gütersloh 1951).

Die probleem waarmee hierdie boek te doen het, is hoe om die Evangelie aan die moderne wêreld te bring. Die skrywer gee kort maar duidelik weer hoe die moderne wetenskap, en hiervandaan uit die moderne wêreldbeskouing, los van die Evangelie geraak het. Die moderne Europese mens het vir 'n baie groot deel heeltemaal niks meer met godsdiens te doen nie, en vir 'n ander groot deel is die godsdiens in die lewe van die mens teruggedruk sodat dit maar een klein hoekie vul; die res word deur 'n ontkerstende wetenskap oorheers.

Die skrywer wyt hierdie toedrag van sake aan die Protestantisme wat heeltemaal eensydig ontwikkel het. Hy sê dat ons die drie groot christelike groepe kan tipeer as die Petriniese stylvorm (Rooms Katolisisme), die Johaneiese stylvorm (die Grieks en Russies Ortodokse Kerk) en die Pauliniese stylvorm (Protestantse Kerke). Die Protestantse Kerke het egter net een (hoewel inderdaad die allerbelangrikste) element uit die briewe van Paulus geneem, nl. die persoonlike verhouding van die individu tot God. Die ander belangrike element, nl. die kosmiese betekenis van die koms en wederkoms van Christus, die kosmiese betekenis van die verlossingswerk van Christus en van die versoening van die mens, is heeltemaal op die agtergrond gedring. Hierdie kosmologie is in die Oosterse Kerke behou, omdat in die Westerse Protestantisme die hele godsdiens op die agape van God en in die Oosterse Kerke op die sophia van God gebou is. Die skrywer toon dan hoe daar in die Oosterse Kerk steeds die band met die wetenskap gehou is, terwyl dit in die Weste verlore gegaan het; waar die filosofie bv. in die Weste dikwels te voorskyn tree as die aartsvyand van die godsdiens, ken die Ooste eintlik alleen 'n godsdiensfilosofie. 
Die skrywer verlang dan 'n integrasie van die Evangelie in die wêreld van die wetenskap. Egter nie 'n integrasie wat vereis dat die werklike godsdienstige inhoud van die Evangelie verlore gaan (soos in Bultmann se ,Entmythologisierung" van die N.T.) nie, maar 'n integrasie waar die Evangelie in sy volle skriftuurlike gesag gehandhaaf word. Hiervandaan kom dan ook die kritiek van die skrywer op die dialektiese teologie: hoewel die skrywer in sekere opsigte Karl Barth in grootheid en belang naas Luther wil rangskik, noem hy tog die dialektiese teologie ' $n$ isolasieteologie wat 'n ontvlugting van die moderne problematiek beteken.

Om hierdie integrasie moontlik te maak, stel die skrywer 'n verdeling van die wetenskap in twee groot groepe voor, $\mathrm{nl}$. die antropologiese groep en kosmologiese groep. Elkeen van die groepe het 'n grondwetenskap as vooronderstelling, $\mathrm{nl}$. 'n christelike antropologie en 'n christelike kosmologie. Dit beteken egter nie dat die Christendom vir die wetenskap moet voorskrywe wat om te verkondig nie - die wetenskap het 'n „Eigengesetzlichkeit” wat hy moet nakom om wetenskap in die volle sin te kan wees; hieroor het die Christendom niks te sê nie. Maar die wetenskap sedert die Renaissance ly aan 'n ,Eigenmächtigkeit" waardeur die wetenskap wil probeer om vanuit wetenskaplike gegewens die laaste sin en betekenis van die wêreld, die geskiedenis en die lewe van die mens an te gee; m.a.w. die wetenskap probeer om die wêreldbeskouing van die mens te vorm en die godsdiens te verdring. Hier is dit waar die godsdiens 'n grens aan die wetenskap moet stel. Egter spreek die godsdiens nie soseer die wetenskap as die wetenskaplike aan nie en die terughoudendheid van die wetenskap hang af van die geloofsbeslissing van die wetenskaplike.

Eers hierdie integrasie maak 'n werklik alomvattende „evangelische Akademie" (Christelike Universiteit) moontlik.

Die skrywer vind drie blywende strukture in die „Eigenmächtigkeit" van die wetenskap, nl. ideologie, idolatrie en utopie, wat 'n wesenssamehang met mekaar het. Dis hierdie strukture wat deur die godsdiens verbreek moet word. Hierteenoor stel hy dan 'n skets van 'n christelike antropologie wat hy by wyse van eksperiment na verskillende kante probeer toepas, bv. in die reg, staat, medisyne, ens.

Die skrywer probeer hier dieselfde as wat die Neo-Calvinisme met die leer van 'n christelike wetenskap probeer; hy het dan ook groot waardering vir Abr. Kuyper. Dillschneider se poging is om verskillende redes vir ons aantrekliker, hoewel maar heel gering wanneer ons dit by die magdom van literatuur van die kant van die Neo-Calvinisme vergelyk. Dillschneider se aantreklikheid lê in die feit dat hy die Bybel so geweldig sterk laat geld, ja selfs in so'n mate dat hy teen die „Konfessionalismus" te velde trek, en dat hy baie sterk eukumenies dink. Egter bly dit maar 'n poging.

Die belang van hierdie werk lê daarin dat dit die probleem van die konfrontasie van die Evangelie met die moderne kultuur baie sterk onder ons aandag bring. Hoewel die boek geen oplossinge bevat nie - 
en dit ook nie pretendeer nie - bied dit suggesties van verskillende moontlikhede wat beproef kan word. Die boek is eenvoudig en helder geskrywe, mooi gedruk en gebind en vorm baie interessante en gedagteprikkelende leesstof.

P. S. Dreyer.

Prof. Dr. A. M. Brouwer, Verzoening, een Bijbelsch-Theologische Studie 290 bls., 14/6, posvry 15s., Neerbosch Boekhandel en Uitgevery, Neerbosch.

Hierdie boek is nie bedoel as ontspanningslektuur nie. Dis 'n boek m.a.w. wat 'n mens nie in 'n ledige uurtjie kan opneem om 'n bietjie vir afleiding daarin te lees nie. Dit vereis ingespanne konsentrasie en 'n vry uitgebreide bybelse en dogmatiese kennis. Die onderwerp, tereg die "hart van die evangelieverkondiging" genoem, is belangrik en veelsydig en daarom ook moeilik om te behandel; die skrywer oordrywe dan ook nie as hy in verband hiermee in sy „Woord Vooraf "sê, dat allerlei vrae uit die hele gebied van die Teologie hulle by die bespreking voordoen, sodat dit maklik sou wees om 'n paar boekdele te vul. Hy wil sy stof egter beperk en op bevatlike wyse die hoofsake saamvat, sodat belangstellende gemeentelede dit ook kan lees. Hy vermy daarom vakterme, of waar hy die gebruik, omskrywe hy hulle. Hy benader die onderwerp veral van bybels-teologiese en nie in die eerste plek van kerklik-dogmatiese kant nie. Dan is daar sekere aanverwante vrae wat hy nader wil toelig, soos bv. wat die offer beteken, hoe Jes. 53 opgevat moet word, wat onder plaasvervanging, onder geregtigheid, onder sonde, onder skuld en onder vergewing verstaan moet word, selfs ook onder versoening. Sy bedoeling is om van die Bybel uit op die genoemde begrippe en onderskeidinge nader in te gaan. Mog hy mistas, bly dit ewewel nog van belang om hierdie vrae aan die orde te stel. Hy hoop dat sy pennevrug daartoe mag bydra om die bybelse verkondiging dieper te verstaan.

$\mathrm{Na}$ die "Woord Vooraf" volg 'n inleidende hoofstuk waarin die skrywer rekenskap van sy onderneming gee. $\mathrm{Hy}$ is nl. herhaaldelik gevra om 'n uiteensetting te gee van wat ons volgens die Skrif onder ,,versoening" moet verstaan. Daar het reeds baie boekdele oor die onderwerp verskyn, maar die skrywer waag tog, na anvanklike aarseling, om daaroor te skrywe, „,omdat ik meen, dat wij het van den Bijbel uit opnieuw moeten benaderen". Hy het nie soseer die oog op beroepsteoloë nie, want hulle het uitvoerige geskrifte tot hulle beskikking, maar dink hoofsaaklik aan gemeentelede wat moeite met die begrip vetsoening het.

$\mathrm{Na}$ die inleiding word in hoofstuk II enkele hoofbegrippe bespreek: God, hoe God te ken, die heilige Skrif, God en mens, sonde, skuld, die oorsprong van die sonde, predestinasie, die Evangelie, sondevergewing, solidarisme, erfsonde, straf. 
Hoofstuk III gaan oor tweeërlei versoenirg, soos dit blyk uit die twee verskillende griekse woorde: katallagé (wegneming van ryandskap) en hilasmos (bedekking van sonde).

In hoofstuk IV word uit die O.T. vereers die offer breedvoerig behandel en vervolgens Jes. 53 (met die vertaling van Obbink daarby).

Hoofstuk V dra as opskrif: Jesus. Jesus het nl. ,enkele aanduidingen gegeven, die wijzen in de richting waarin over $\mathrm{Hem}$ en $\mathrm{Zijn}$ arbeid geoordeeld moet worden" (bls. 90) en dit word in hierdie hoofstuk na. gegaan en toegelig.

In hoofstuk VI word die oudste Christenheid bespreek, waarop in hoofstuk VII uitvoerig (soos ons trouens kon verwag) oor Paulus gehandel word. Dan volg in hoofstuk VIII 'n bespreking oor die brief aan die Hebreërs, in hoofstuk IX: 1 Joh. en 1 Petr., en hoofstuk X handel oor die Persoon van Christus.

In hoofstuk XI word enkele momente uit die Dogmengeskiedenis onder die soeklig geneem -- die ou Kerk, die Middeleeue, die Hervormingstyd, die $19 \mathrm{de}$ eeu, ons tyd, Nederland. Dit word deur die slothoofstuk gevolg onder die opskrif: Samenvatting en Conclusie. Sy "Conclusie" vat hy saam in 'n twaalftal stellinge wat hy kortliks verdedig.

Uit die inhoud (wat hier in kort weergegee is) blyk watter geweldige gebied bestryk word. Taal en styl is goed versorg. Tog moet ek by alle waardering vir wat die skrywer bied, opmerk dat die inhoud my oor die algemeen nie bevredig nie; ek het ook by talle van uitsprake en gevolgtrekkinge 'n vraagteken geplaas. Ek sou graag gesien het dat die skrywer dwarsdeur die hooflyn van sy betoog forser getrek het. Hiermee bedoel ek dit: Die boek sou beslis aan helderheid van voorstelling gewen het as die skrywer van meet af die versoeningsidee behandel het soos dit agtereenvolgens in $\mathrm{O}$. en $\mathrm{N}$. Test. voorkom, sy gevolgtrekkinge uit die Skrifgegewens gemaak, en dan afgesluit het met 'n beknopte dogmenhistoriese oorsig. Die stof is egter nou so ingedeel, dat die skrywer nie heeltemal aan die gevaar van te swaar geladenheid en selfs herhaling kon ontkom nie. Hierby kom, dat die geheel die indruk op my maak van koele, afgetrokke redenering, asof die intellek alleen aan die woord is, terwyl die hart swyg, wat jammer is by 'n onderwerp waarvan die skrywer self getuig, dat dit die ,hart van die evangelieverkondiging" is. Aangesien hy nie allereets beroepsteoloë op die oog het nie, maar gemeentelede, sou 'n bietjie warmte die verdienstelikheid van die werk sekerlik ten goede gekom het. En wat die vraagtekens betref, ek kan daar nie in besonderhede op ingaan nie, omdat dit 'n breedvoerige bespreking sou verg, want belangrike eksegetiese en dogmatiese punte word geraak. $\mathrm{Ek}$ volstaan daarom om net die volgende bedenkinge te noem. (Nie in volgorde van belangrikheid nie; dis net 'n greep).

$\mathrm{Ek}$ het alle waardering vir die objektiewe weergawe van ANSELmus se satisfaksie-leer en die breedvoerige bespreking daarvan, maar m.i. onderskat die skrywer tog ook weer die verdienstelike kenmerke daarvan. 
Dat aan Israelietiese offers alle idee van plaasvervanging ontsê moet word, kan ek nie toestem nie, ewemin dat Christus nie in die mees volstrekte sin van die woord plaasbekledend gely en gesterwe het nie. Hy het met ons, blykens die getuienis van die Skrif, so 'n innige en diepe gemeenskap ingegaan, dat ons ons daar geen voorstelling en geen begrip van kan maak nie, en dit word selfs deur die woorde plaasvervangende (plaasbekledende) lyde en sterwe nog maar op baie floue en gebrekkige wyse uitgedruk. Vgl.: satisfecit caput pro membris, Christus pro visceribus suis (Bernard). Ek stem toe dat die voorsetsels wat weergegee word deur "vir ons", in die Skrif nie ,in die plek van" ons beteken nie, maar ,ten behoewe van" ons, ,terwille van” ons (bls. 263), maar dan wil ek tog konstateer, dat hierdie voorsetsels tussen die offer van Christus en ons sonde 'n sodanige verband lê, dat die idee van plaasvervanging daarby nie gemis en daaruit nie verwyder kan word sonder om die klaarblyklike bedoeling van die Skrif geweld aan te doen nie. Hieruit volg dat ek my ook nie kan vereenselwig met die stelling dat Christus die toekomstige straf van die eindoordeel nie gedra het nie. Dat Christus nie die plek van die sondaar ingeneem het nie (plaasvervanging), maar Hom een met die sondaar gemaak het (solidêrstelling), vind ek 'n uiters bedenklike veroppervlakkiging van die lyde, sterwe en opstanding van Christus. Ek kan daarom dan ook die opvatting van die skrywer t.o.v. Jes. 53 nie deel nie. Op watter grond die skrywer kan beweer dat daar nêrens in die Bybel geleer word, dat die geloof self 'n genadegawe is nie en dit 'n „onbijbelsche gedachte" noem, is vir my heeltemal duister. Die skrywer onderskei ook twee momente in die regverdiging - 'n ,,voorlopige" nou in hierdie lewe, en 'n ,uiteindelike" wanneer die mens by die eindoordeel die ,eeuwige leven" vergoed ingaan. Die bedoeling is blykbaar goed, maar ek het beswaar teen die formulering, omdat dit maklik aanleiding tot misverstand gee. Natuurlik sal die volle vrug van die regverdiging eers gesmaak word wanneer op die jongste dag ook die liggaam verlos is en God die vryspraak van Sy geregverdigdes ten aanhore van die heelal afkondig. Daar is etlike punte meer waarin ek prinsipiëel van die skrywer verskil, maar genoeg. Al stem die belangstellende leser nie in alles met die sienswyse van die skrywer saam nie, sal die lees van die boek hom altans aanspoor om homself te besin en rekenskap te gee van sy geloofsoortuiging, wat op homself al 'n groot winste is.

Die boek is stewig gebind en die druk is helder; wat dit betref, het die uitgewer (Neerbosch' Boekhandel en Uitgeverij, Neerbosch) alle eer; dis alleen jammer dat die gehalte van die papier nie beter is nie, wat egter onder die huidige omstandighede wel verstaan kan word. Verder is die boek van 'n uitvoerige register van persone en sake, asook van 'n register van aangehaalde bybeltekste, voorsien, wat inderdaad waardevol is.

D. F. ERasmus. 
Echter Bibel, Hiob und Sirach.

\section{Neu-Testamentliches Teil.}

Prof. Dr. Th. L. Haitjema. Nederlands Hervormd Kerkrecht, Callenbach, Nijkerk, 1951.

Immanuel Hirsch, Geschichte der nueren evangelischen Theologie, Lieferung 12-16, Berthelmann Verlag. Gütersloh.

Dr. A. v. D. Hoeven. De karakteristiek van de vier evangeliër, Bosch en Keuning, Baarn, s.j.

ERnst Lohmeyer, Das Evangelium des Markus, Vandenhoeck en Ruprecht Göttingen, 1951.

Dr. C. G. van Niftrik, -Zie de mens, Callenbach, Nijkerk, 1951. Ds. S. J. Porma, Het gezegende leven, Bosch en Keuning, Baarn, s.j.

\section{INGEKOME TYDSKRIFTE}

Nederlands Theologisch Tijdschrift, Oct. 1951. Uitg. H. Veenman en Zonen, Wageningen, 6de Jaarg., afl. 1. Inhoud: Prof. Dr. P. A. H. De Boer, De functie van de Bijbel. Dr. W. F. Zuurderg, Hermeneutics. Prof. Dr. W. C. van UNik, Een dissertatia over Hervormde eredienst (Dr. E. van der Schoot). Bibliographisch gedeelte.

Afl. 2, Dec. 1951: Dr. A. F. J. KLIJN, Enige mededelingen betreffende de textcritiek van het Nieuwe Testament. Dr. A. F. N. Lekkerkerker, Gereformeerde liturgiek in de zestiende eeuw. Prof. Dr. TH. C. VRIfzen, Bijbel, Woord Gods en theologie. Prof. Dr. P. A. H. de Boer, Via media? Prof. Dr. J. de ZwaAn, Mededelingen: Codex D en Emmaus. Bibliographisch gedeelte.

Kerk en Teologie, Uitg. H. Veenman en Zonen, Wageningen. 2de Jaarg. No. 3, Juli 1951. Ds. F. R. A. Henkels, De keukenmeid. Prof. Dr. K. H. Miskotte, Controvers-gesprek met Karl Barth. Dr. A. F. N. Lekkerkerker, De aard van Christus' tegenwoordigheid in het Avondmaal, Dr. J. G. Woelderink, De Volkskerk. Prof. Dr. G. C. van Niftrik en Dr. A. F. N. LeKKerkerker, Kroniek. Boek bespreking.

No. 4, Oct. 1951. Prof. Dr. A. A. van Ruler, De reformatie en de una sancta. Prof. Dr. K. H. Miskotte, Schepping en Verbond. Prof. Dr. Th. L. Haitjema, Schriftgeloof en exegese. Prof. Dr. Harmannus Obendiek, De apostolische opdracht der kerk. Dr. J. G. Woelderink, Volkskerk en apostolaat. Prof. Dr. G. C. van Niftrik, Kirchliche Dogmatik III, 4. Prof. Dr. G. C. van Niftrik en Dr. A. F. N. LekKerKERKER, Kroniek. Boekbespreking. 
3de Jaarg., No. 1, Jan. 1952. Ds. F. H. Breukelman, Koninkrijk der hemelen. Dr. F. de Graaf, Randfiguren. Prof. Dr. de Vos, Nietzsche en Heidegger randfiguren van het Christendom? Prof. Dr. TH. L. Haitjema, De Rooms-Katholieke synthese tussen persoonlijk geloof en kerkelijk leergezag. Ds. W. H. Kelder JR, Kerkmuziek. DR. A. F. N. Lekkerkerker, Dienstboek en Kerkmuziek. Prof. Dr. G. C. van Niftrik en Dr. A. F. N. LekKerkerker, Kroniek. Boekbespreking.

Th.e W'estern Seminary Bulletin, Reformed Church in America, Holland, Michigan. Vol. V, No. 1, May 1951. Simon Blocker, God's Redemptive Judgements. JohN W. Hollenbach, The Novel as a Religious Experience. JoHN A. VAN DER WAAL, The individual in Kierkegaard. Seminary Highlights. Book Reviews.

Vol. V, No. 2, Sept. 1951. Henry A. Popppen, The Forgotten Factor, God. Richard C. Oudersluys, Preaching the Parables and Miracles of Jesus. Rober t B. Wildman, Faith and the Abundant Life. A Study in Psychology. Seminary Highlights. Book Reviews.

Vol. V, No. 3, Dec. 1951. Lester J. Kuyper, The Message of Apocalyptic. Thomas Bosiooper, Recent Studies in Eschatology. Seminary Highlights. Book Reviews.

Verbum Domini. Pontificium Institutum Biblicum, Roma, Vol. 29, Fasc. 1. P. Gutierrez, Conceptus "Lucis" apud Iohannem Evangelistam in relatione ad conceptam "Veritatis". P. Kacur, De textu Ioh. I, 14c. C. Latrey, De baptismo activo Christi. H. Kruse, Archetypus Psalmi 104, (103). M. Zerwick, Vivere ex Verbo Dei : (2) "In Beelzebub, principe daemoniorum" (Lc. 11, 14-28). Spectator Ephemeridum. Bibliographiз.

Vol. 29, Fasc. 2. Theoph. Aв Orbiso, Christiana sinceritas (Jac. $5: 12$ ). BAld. Kipper, De origine mosaica "Libri Foederis". St. Lyonnet, "Constituerunt ei triginta argenteos" (Mt 26,15). M.Z., "Qui venturus est". R. Deville, Assidua lectio S. Scripturae . . . iuxta Maldonatum. Spectator Ephemeridum. Bibliographia.

Vol. 29, Fasc. 3. J. T. Milik, "Manuale disciplinae". Bald. Kipper, De origine Mosaica "Libri Foederis" (II). M.Z., In via ad integritatem veritatis. Spectator Ephemeridum. Bibligraphia. 